\title{
Dynamic Characteristics of the Rotating Penetrating Missile for Attacking Warship Vertically
}

\author{
Dong-ze Qin (i) and Pei-hang Li \\ School of Mechatronic Engineering, North University of China, Taiyuan 030051, China \\ Correspondence should be addressed to Dong-ze Qin; apo1981@126.com
}

Received 26 March 2021; Accepted 5 July 2021; Published 20 July 2021

Academic Editor: Francesco Tornabene

Copyright (C) 2021 Dong-ze Qin and Pei-hang Li. This is an open access article distributed under the Creative Commons Attribution License, which permits unrestricted use, distribution, and reproduction in any medium, provided the original work is properly cited.

\begin{abstract}
The paper aimed to analyze the dynamic response of a new type penetrating missile in rotary attacking warship. The dynamic response characteristics of the penetrator become more complex when attacking the ship target due to the special materials of the deck such as stiffeners. Therefore, different from attacking other targets, the article reveals the design rules of precession penetration ammunition and fuze. A physical model of the missile target is established to study the numerical simulation of the penetration process of rotating projectile into a stiffened target based on finite element analysis (FEA) software. We studied the dynamic response characteristics of different projectile positions, rotational speeds, and positions that act in precession penetration. As experimental results show, the residual velocity of the precession penetrator decreases with the distance between the projectile point and stiffener. When the projectile penetrates the second target plate, the acceleration is greater than that in the first layer. It is proved that the deflection angle of the shell body is affected by comprehensive factors. The rotational speed in the projectile has less contribution to precession penetration ammunition. In addition, the change of acceleration in the missile's central section can be significantly perceived in the direction perpendicular to the penetration direction.
\end{abstract}

\section{Introduction}

1.1. Background. The rotating penetrating projectile is not only a new type of penetration ammunition but also an effective supplement when it is applied to attack ship targets. With the improvement of the warship's armor structure design, the antipenetrating effectiveness of the deck is showing a substantial promotion. Unlike the traditional homogeneous target plate, the special design of the ship deck (e.g., transverse or longitudinal T-stiffener) will have a great influence on the performance of the projectile.

Literature [1] introduced a high rotating speed missile penetrating into moving vehicle doors at a different incident angle. Literature [2] introduced rotating penetrating missile numerical simulation and experimental in bunker buster.
Literature [3] introduced an investigation of the penetration resistance of monolithic and double-layered steel plates. Literature [4] introduced an experimental and numerical investigation on the ballistic resistance of double-layered steel plates. Literature [5] introduced a computational investigation of ballistic impact behavior and penetration resistance of a nacre-like ceramic/polymer-laminated composite. Literature studies [6-11] introduced the response of different protective materials during penetration and revealed the relevant laws. Literature studies [12-16] introduced the analysis and experiments of antiship target penetration and revealed relevant laws.

The results of the relevant literature show that the numerical analysis method for penetration is mature. However, it can be seen that there is relatively little research in the ship 
of the rotating penetrating, and the relevant laws are not clearly understood, which has caused certain constraints on the design of the rotating penetrating missile.

\subsection{Contributions}

(1) In this paper, we established the physical model of missile into the target. Under different working conditions, the numerical simulation is applied to analyze the penetration process of the projectile to the stiffened target by FEA.

(2) This research provides five contributions. The residual speed of the novel rotating penetrating missile decreases with the reduction of the distance of the projectile point relative to the reinforcing ribs. The acceleration of the missile penetrating the second target is larger than that of the first one. The combined factors affect the deflection angle of the missile. The rotational speed of the projectile affects the penetration of precession ammunition weakly. Finally, the acceleration change perpendicular to the penetration direction is more obvious in the middle of the missile.

\section{Simulation Model}

2.1. Procedure. As follows, the research is based on ANSYS/ workbench LS-DYNA for simulation analysis.

Step 1: 3D modeling software was used to build a simulation geometry model

Step 2: call the LS-DYNA module on the ANSYS/ WORKBENCH, add geometric models, and set material parameters

Step 3: preprocessing: specifically, including meshing, defining contact, applying loads, and boundary conditions, etc.

Step 4: solve: The LS-DYNA module is used to solve it with its own solver

Step 5: postprocessing: the relevant result file generated after step 4 is solved, imported into LS-POST postprocessing software, and generated the required data and charts

Step 6: analysis of simulation results.

2.2. Finite Element Model. Assuming the target is a warship, the steel is HY-80, its characteristics are comparable with the 921A steel, so choose the 921A steel in the software material library $[14,16]$. Target plate size settings: $1400 \mathrm{~mm}$ long; $1000 \mathrm{~mm}$ wide; deck thickness, $15.2 \mathrm{~mm}$; large rib height, $68 \mathrm{~mm}$; width, $15.2 \mathrm{~mm}$; small rib height, $26 \mathrm{~mm}$; width, $7 \mathrm{~mm}$; small rib spacing, $125 \mathrm{~mm}$; large rib spacing, $600 \mathrm{~mm}$, as shown in Figure 1.

The missile is chosen to cut the truncated ogive nose. The intercepting diameter (d) is about $1 / 5$ of the projectile diameter (D). The truncated ogive nose's head is a wall-to-wall thick head shell, gradually thinning from the apex axis to the "first-column" excessive area, the thickest at the top is 5

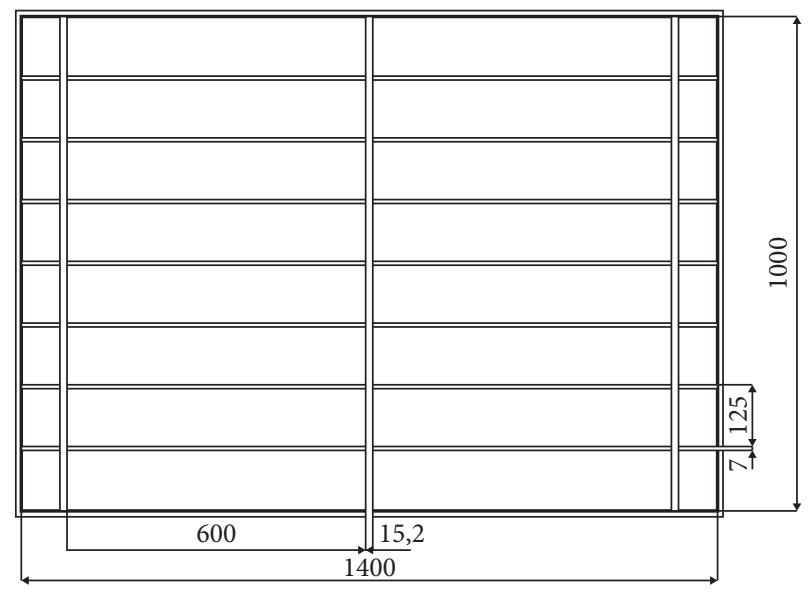

FIgURE 1: Target plate structure diagram.

times the thickness of the wall, and the wall thickness of the column segment is $10 \mathrm{~mm}-14 \mathrm{~mm}$. The missile body is $370 \mathrm{~mm}$ long, the projectile diameter is $105 \mathrm{~mm}$, the missile head is egg-cut, the cut head diameter is $20 \mathrm{~mm}$, and the arc radius of the missile body is $180 \mathrm{~mm}$. The projectile material is $30 \mathrm{CrMnSiNi} 2 \mathrm{~A}$, and the explosives and fuze in the missiles are treated with elastic material. Among them, the loading density is $1.7 \mathrm{~g} / \mathrm{cm}^{3}$, the fuze density is $3.8 \mathrm{~cm}^{3}$, and the total mass of the missile body is $16 \mathrm{~kg}$.

In order to reduce the calculation, the target analysis process is assumed to be two-layered on the basis of generality. The finite element model of the target and the missile is shown in Figure 2.

The structure of this article is modeled and analyzed using 3D solid164 units. Taking into account the accuracy and timeliness of the calculation, the mesh is dense and the mesh in the rest of the area is sparse in the $200 \mathrm{~mm}$ square area with a $200 \mathrm{~mm}$ square length at the center edge of the target board. On the intersection of the dense and sparse areas of the mesh, the mesh performs a good transition, which avoids the reflection of the stress wave on the transition. The grid size convergence analysis shows that the calculation is stable at a fixed level and the duration is acceptable. Each calculation takes about 6 hours. Table 1 shows the grid size of each part.

The cell grid ratio is within the normal range and is dense and reasonable, and the mesh quality is higher. This shape and size mesh is used for calculation, and the results are reliable.

2.3. Constitutive Equations. Since both $921 \mathrm{~A}$ steel and $30 \mathrm{CrMnSiNi2 \textrm {A }}$ are temperature-sensitive materials, the Johnson-Cook model is used. The equation for this structure is [14-16]

$$
\sigma_{y}=\left(A+B \bar{\varepsilon}_{p}^{n}\right)(1+C \ln \stackrel{\cdot *}{\mathcal{\varepsilon}})\left(1-T^{* m}\right),
$$

where $A, B, C, n$, and $m$ is the material in the formula, $\bar{\varepsilon}_{p}^{n}$ is an equivalent plastic strain, $\stackrel{*}{\varepsilon}=\bar{\varepsilon}_{p} \cdot / \dot{\varepsilon}_{0}$ is the plastic strain ratio, generally taken $\varepsilon_{0}=1.0 \mathrm{~s}^{-1}, T^{*}=\left(T-T_{r}\right)\left(T_{m}-T_{r}\right)$ is the relative temperature, $T_{r}$ is the room temperature, and $T_{m}$ is the melting point temperature. 


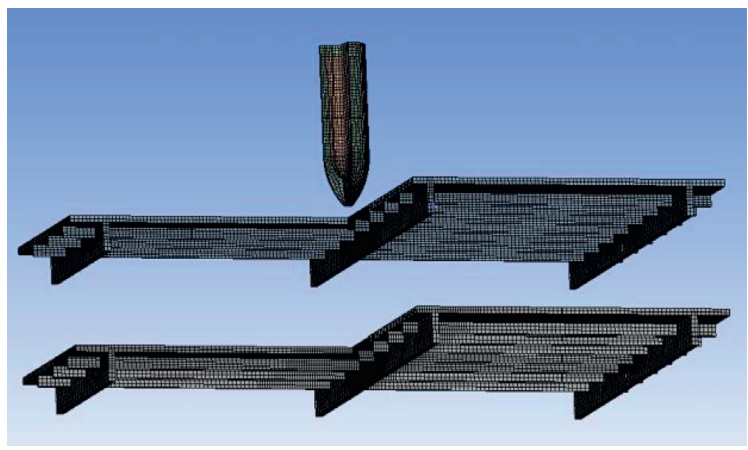

Figure 2: Reinforcing rib plate and missile's finite element model.

TABLE 1: Unit size of each part.

\begin{tabular}{lcccc}
\hline Parts & Target plate dense area & Target plate sparse area & Bullet & Loading \\
\hline Regional $(\mathrm{mm})$ & 8 & 10 & 5 & 5 \\
\hline
\end{tabular}

TABLE 2: 921A steel John-Cook material model constant $[14,15,16]$.

\begin{tabular}{lccccccr}
\hline$\rho(\mathrm{kg} / \mathrm{m})$ & $\mathrm{E}(\mathrm{GPa})$ & $\mathrm{U}$ & $\mathrm{Tr}(\mathrm{K})$ & $\mathrm{Tm}(\mathrm{k})$ & $\mathrm{A}(\mathrm{MPa})$ & $\mathrm{B}(\mathrm{MPa})$ & $\mathrm{N}$ \\
\hline 7800 & 205 & 0.28 & 298 & 1765 & 490 & 807 & 0.73 \\
$\mathrm{C}$ & $\mathrm{m}$ & $\mathrm{D} 1$ & $\mathrm{D} 2$ & $\mathrm{D} 3$ & $\mathrm{D} 4$ & $\mathrm{D} 5$ & 0.015 \\
0.0114 & 0.94 & 0.8 & 1.732 & -0.54 & -0.00 & 0 \\
\hline
\end{tabular}

Table 3: 30CrMnSiNi2A steel John-Cook material model constant $[14,15,16]$.

\begin{tabular}{lccccccc}
\hline$\rho(\mathrm{kg} / \mathrm{m})$ & $\mathrm{E}(\mathrm{GPa})$ & $\mathrm{U}$ & $\operatorname{Tr}(\mathrm{K})$ & $\operatorname{Tm}(\mathrm{k})$ & $\mathrm{A}(\mathrm{MPa})$ & $\mathrm{B}(\mathrm{MPa})$ & $\mathrm{N}$ \\
\hline 7850 & 211 & 0.3 & 298 & 1798 & 1269 & 810.18 & 0.479 \\
$\mathrm{C}$ & $\mathrm{m}$ & $\mathrm{D} 1$ & $\mathrm{D} 2$ & $\mathrm{D} 3$ & $\mathrm{D} 4$ & $\mathrm{D} 5$ & 0 \\
0.040 & 1 & 0.239 & 8.593 & 7.867 & 0.009 & 0 \\
\hline
\end{tabular}

Break strain is

$$
\varepsilon_{f}=\left(D_{1}+D_{2} \exp D_{3} \sigma^{*}\right)\left(1+D_{4} \ln ^{g *} \mathcal{\varepsilon}\right)\left(1+D_{5} T^{*}\right),
$$

where $\sigma^{*}=p \sqrt{\sigma}$ is the ratio of hydrostatic pressure to equivalent stress and $D_{i}$ is a constant in the formula.

When defining a material with the Johnson-Cook model, it is necessary to combine the Gruneisen state equation, which can define the relationship between the pressure volume in two ways to determine whether the material is compressed or expanded. The Gruneisen state equation with a three-dimensional impact velocity of one particle defines the pressure of the compressed material as follows:

$$
P=\frac{\rho_{0} C^{2} \mu\left[1+\left(1-\gamma_{0} / 2\right)\right] \mu-a / 2 \mu^{2}}{[1-(S-1) \mu]^{2}}+\left(\gamma_{0}+a \mu\right) E
$$

In the formula, $C$ is the intercept of the $v_{S}-v_{P}$ curve, $S$ is the $v_{s}-v_{p}$ slope coefficient, $\gamma_{0}$ is the Gruneisen constant, and $a$ is the first-order volume correction of $\mu=\rho / \rho_{0}^{-1}$. The material model parameters of the target system are set in Tables 2 and 3 .
2.3.1. Boundary Condition Settings. A fixed restraint is used on the four sides of the reinforced rib target plate. For the structure, the type of the contact set is CONTACT AUTOMATIC_GENERAL which ensures effective contact between individual components and between components. In the calculation of complex structural, contact nodes and surfaces are difficult to predict, and the contact type is introduced to avoid penetration by unpredictable contact. The type of contact between the missile and the target board is CONTACT_ERODING_SINGLE_SURFACE. Erosion contact is a common method in simulation calculation. During the invasion, the phenomenon of fragmentation of the missile and target plate is obvious, and the failed unit is deleted in large numbers, thus causing the original contact interface to be destroyed. To make the surface unit be largely deleted, the internal unit can still effectively contact, do not penetrate, use erosion contact, and can effectively solve the contact problem.

2.3.2. Time Integration Scenario. The calculation time is set to $1.2 \mathrm{~ms}$. The maximum energy error's value is 0 . The time step safety factor is 0.6. 


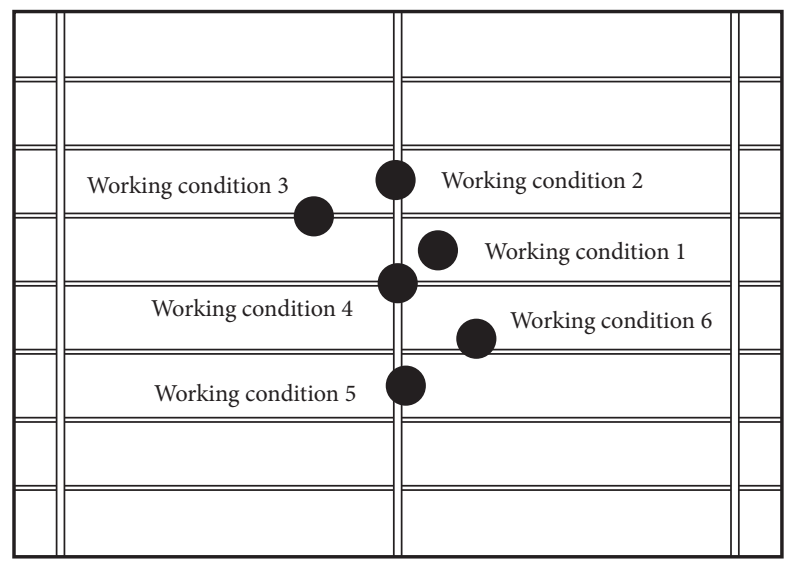

Figure 3: Missile position.

TABLE 4: Schedule of work.

\begin{tabular}{lcccccc}
\hline & Working condition 1 & $\begin{array}{c}\text { Working } \\
\text { condition } 2\end{array}$ & $\begin{array}{c}\text { Working } \\
\text { condition } 3\end{array}$ & $\begin{array}{c}\text { Working } \\
\text { condition } 4\end{array}$ & Working condition 5 & Working condition 6 \\
\hline $\begin{array}{l}\text { Missile } \\
\text { position }\end{array}$ & $\begin{array}{c}\text { Hitting the plate } \\
\text { between the } \\
\text { reinforcing ribs }\end{array}$ & $\begin{array}{c}\text { Hitting the } \\
\text { big ribs }\end{array}$ & $\begin{array}{c}\text { Hitting the } \\
\text { little ribs }\end{array}$ & $\begin{array}{c}\text { Hitting the size rib } \\
\text { intersection point }\end{array}$ & $\begin{array}{c}\text { Intercepting the arc of } \\
\text { the head penetrate the } \\
\text { big ribs }\end{array}$ & $\begin{array}{c}\text { Intercepting the arc of } \\
\text { the head penetrate the } \\
\text { small ribs }\end{array}$ \\
\hline
\end{tabular}

\section{Numerical Simulation Results and Analysis}

3.1. Impact of Missile Position. The target deck composed of stiffeners is heterogeneous, which leads to the different impact points of the projectile relative to the target. Therefore, the forces on the structure of the missile are also different. The relative position relationship between the projectile point target plate reinforcement is shown in Figure 3. Table 4 describes the six main working conditions of the impact point. Because most warships use the vertical skeleton type, the spacing of the horizontal reinforcing ribs is usually large, the probability of working conditions 2 and 4 is relatively small, and is not the most dangerous case of target plate breakage failure. Therefore, this paper mainly studies the dynamic response characteristics of the cyclones under working conditions $1,3,5$, and 6 .

It is assumed that the impact velocity of the missile penetrating the target is $1300 \mathrm{~m} / \mathrm{s}$ and the rotation velocity is $10000 \mathrm{r} / \mathrm{min}$. When the missile is hitting the target plate, the above four conditions (condition 1, condition 3 , condition 5 , and condition 6) are simulated, respectively.

Figure 4 shows a stress cloud map of the missile in four working conditions that have just penetrated through the second target plate. It can be seen that the target plate projectile hole is approximately oval, the missile hole diameter is slightly larger than the projectile body diameter, the edge of the projectile hole on the back of the target plate forms a turned lip (the front of the target petal deformation), and the area of the missile hole collapse is slightly larger than the cross-sectional area of the missile body. As shown in Figure 5, when the truncated surface of the missile penetrates into the stiffener in the working conditions 5 and 6 , the stiffener struck by the projectile during the penetration process will produce obvious bending deformation away from the direction of it under its impact. This phenomenon is induced by the intrusion of the missile. Under the action of compressive resistance, the target plate material in the minimum resistance direction produces plastic flow, which makes the back surface of the target bulge in the direction of penetration. Then, cracks are formed so that the missile body is exposed from the bulge to form the lip behind the target. At the same time, on the stiffeners perpendicular to the plane of the target plate, the bending phenomenon tends to deviate from the direction of the projectile.

Figures 6,7 , and 8 show the time curve of the speed, acceleration, and ballistic offset angle changes in the $Z$-direction of the missile centroid under the above four working conditions.

As can be seen from Figure 6 that when penetrating the reinforcing rib target plate, the projectile point position is different and the speed drop of the body also has obvious differences. It is caused by the different positions of the missile relative to the plate and the corresponding different equivalent penetration thickness. The equivalent penetration thickness of the missile to the stiffener is inversely proportional to the residual velocity of the projectile. Figure 7 shows the graph of the acceleration in the $Z$-direction during the penetrating of speed fixing. From Figure 7 , it can be seen that the overall trend of acceleration changing over time in the four working conditions is the same, while the acceleration when the missile body penetrates the second target plate is significantly greater than the acceleration when penetrating the first target plate. The reason of this phenomenon is the plastic deformation of the missile in the process of penetrating the target plate, which makes the warhead blunt. Because of the increase of the contact area between the projectile and the target, the penetration resistance of the missile is forced to increase 


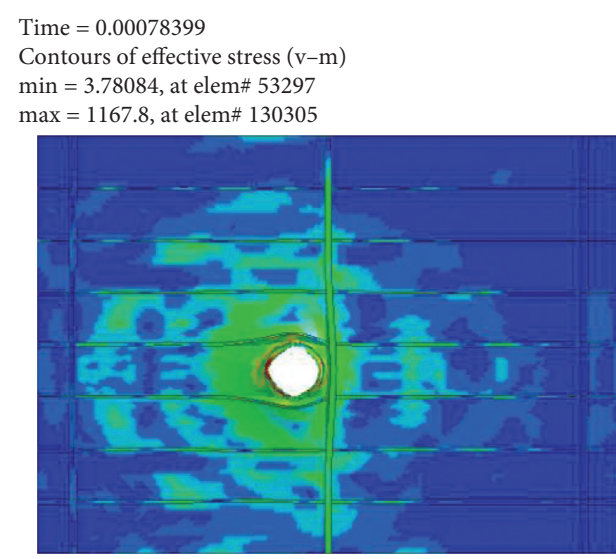

(a)

\section{Time $=0.00063999$}

Contours of effective stress (v-m)

$\min =2.88345$, at elem\# 33525

$\max =1188.84$, at elem\# 56732

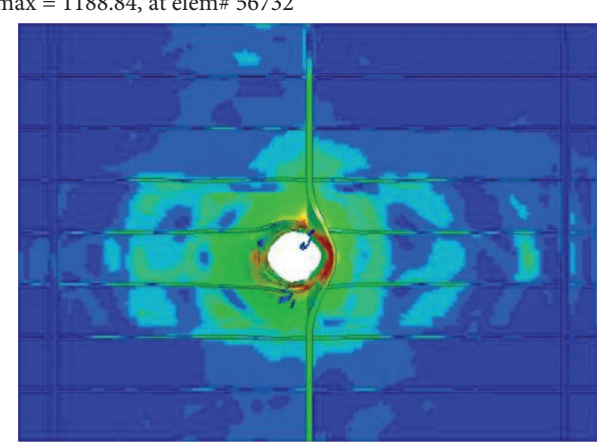

(c)
Time $=0.00063999$

Contours of effective stress $(\mathrm{v}-\mathrm{m})$

Effective stress $(\mathrm{v}-\mathrm{m})$

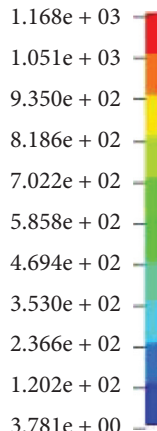

$3.781 \mathrm{e}+00$
Effective stress ( $\mathrm{v}-\mathrm{m})$

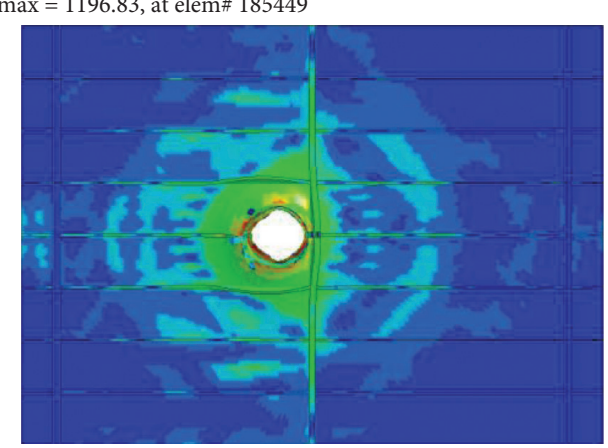

$1.197 \mathrm{e}+03$
$1.077 \mathrm{e}+03$
$9.579 \mathrm{e}+02$
$8.384 \mathrm{e}+02-$
$7.189 \mathrm{e}+02-$
$5.995 \mathrm{e}+02-$
$4.800 \mathrm{e}+02-$
$3.605 \mathrm{e}+02-$
$2.410 \mathrm{e}+02-$
$1.216 \mathrm{e}+02-$
$2.097 \mathrm{e}+00$

(b)

Time $=0.00075199$

Contours of effective stress $(\mathrm{v}-\mathrm{m})$

$\min =3.49437$, at elem $\# 255334$

Effective stress $(\mathrm{v}-\mathrm{m})$

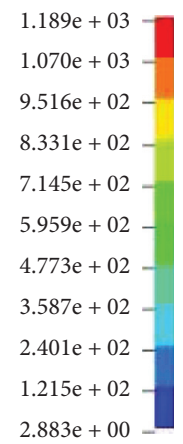

$\max =1171.71$, at elem $\# 142151$

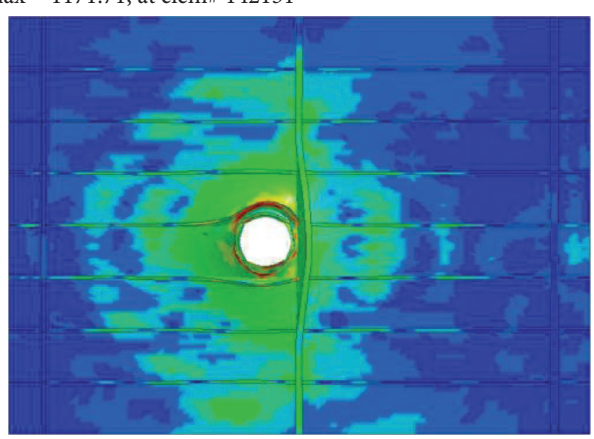

Effective stress $(\mathrm{v}-\mathrm{m})$

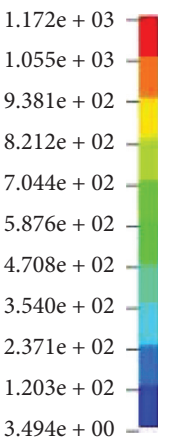

(d)

FIgURE 4: Target plate stress cloud chart. (a) Working condition 1. (b) Working condition 3. (c) Working condition 5. (d) Working condition 6 .

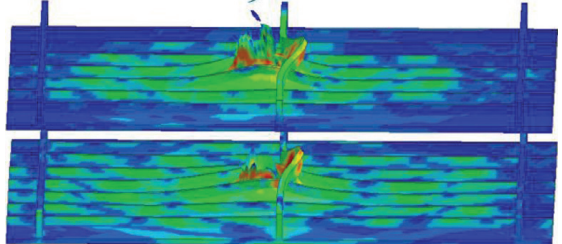

(a)

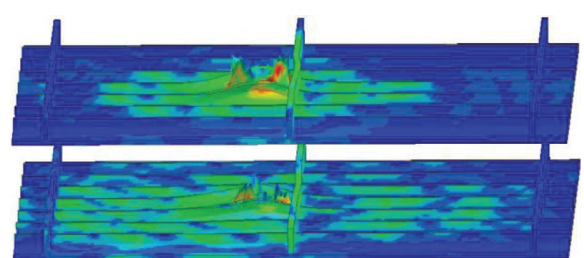

(b)

Figure 5: Target plate missile hole structure. (a) Working condition 5. (b) Working condition 6.

during the penetration of the second target plate. In addition, due to the different impact points, the erosion and pier thickness of the warhead are different when the missile penetrates the first target plate. Therefore, the acceleration difference is obvious when the body penetrates the second one. Figure 8 shows speed fixed when the trajectory deflection angle changes the time graph. A number of factors work together to determine the angle of deflection of the missile. When the projectile body impacts the flat part of the target plate in the forward direction, the overturning torque of the missile is small due to the uniform equivalent penetration thickness. The main performance of the system is the gyro stability, and the deflection angle of the missile body is the minimum simultaneously. When the truncated surface invades the stiffener, the flip torque produced by the projectile is greater than the gyro stabilization effect. Therefore, the ballistic offset angle increases, which is due to the different equivalent penetration thickness on both sides of the missile.

3.2. Speed Effects. It is the most common phenomenon that the curved part of the truncated body penetrates the reinforcing ribs of the target. In order to study the influence of rotational speed on precession penetration, the above condition (5) is simulated as the research object. Among 


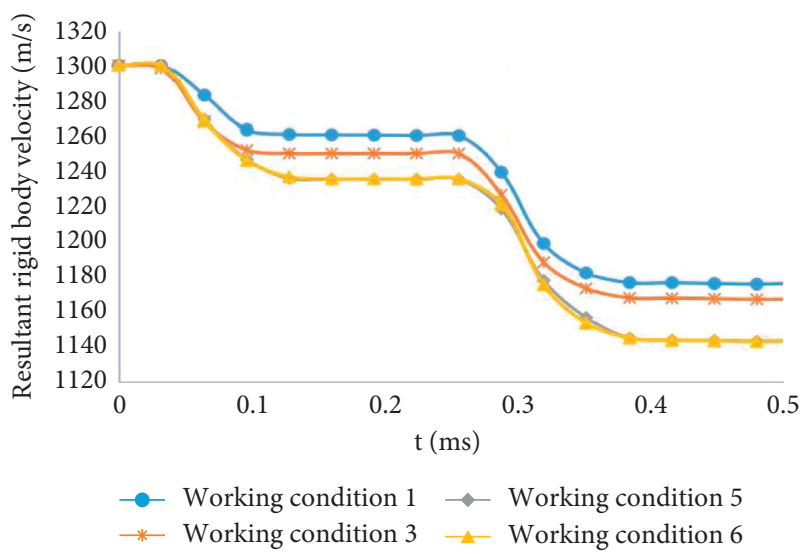

Figure 6: The change of projectile speed.

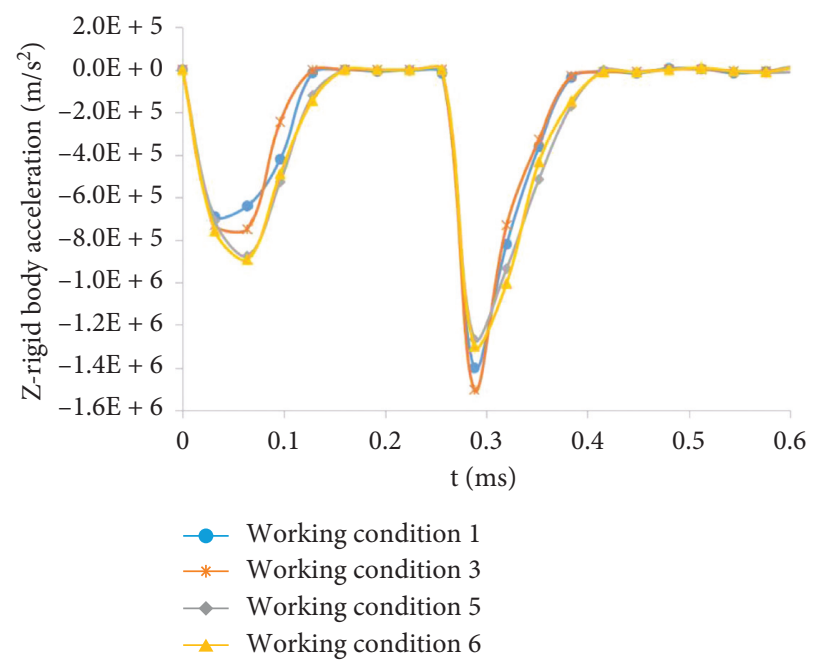

Figure 7: The change of the acceleration of the missile body.

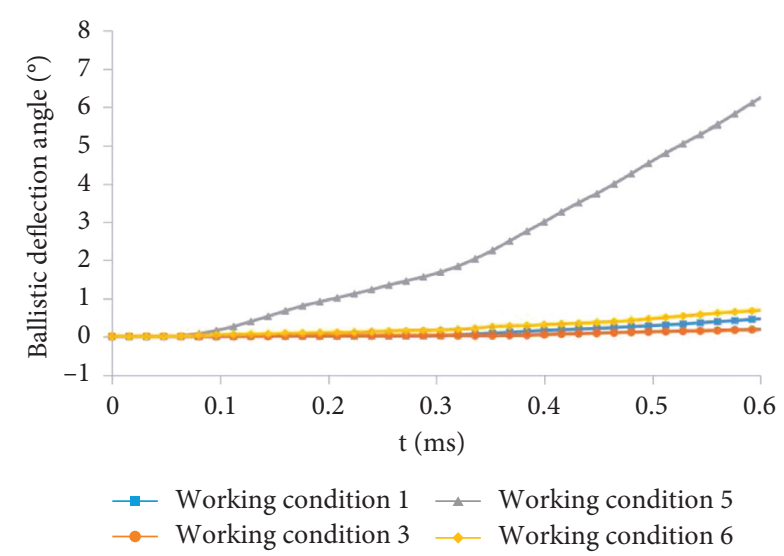

FIGURE 8: Ballistic offset angle change of the missile body.

them, the initial velocity of the missile is $1300 \mathrm{~m} / \mathrm{s}$ and the rotational angular velocity is $0 \mathrm{r} / \mathrm{min}, 5000 \mathrm{r} / \mathrm{min}, 10000 \mathrm{r} /$ $\mathrm{min}$, and $20000 \mathrm{r} / \mathrm{min}$.

Figures 9,10 , and 11 shows the time curve of the velocity, acceleration, and ballistic offset angle changing in the $Z$ -

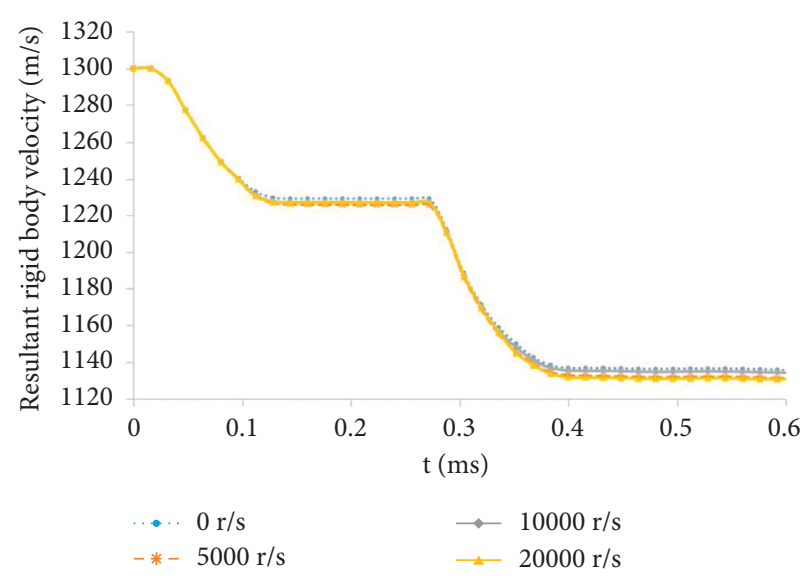

FIGURE 9: Intrusive speed graph when the speed changes.

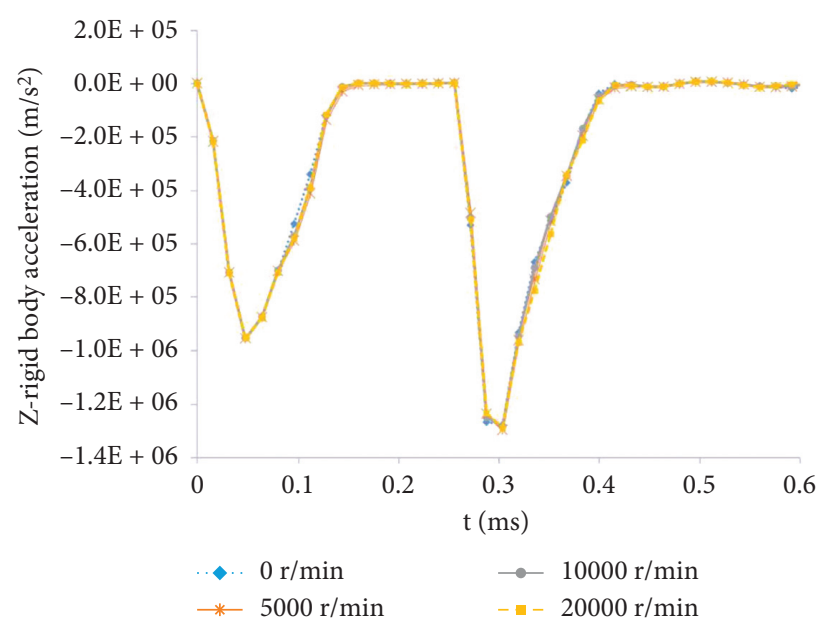

Figure 10: Invasive acceleration graph when the speed changes.

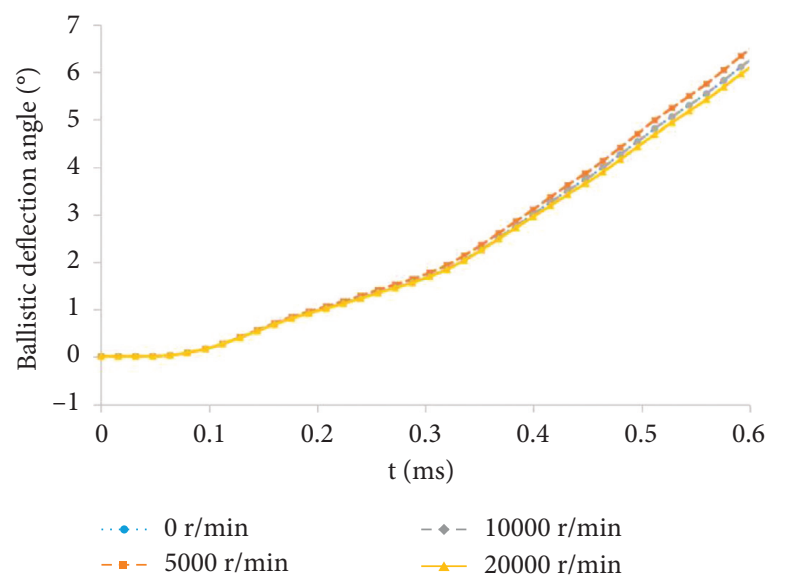

FIGURE 11: Ballistic offset angle changes over time when the speed changes.

direction of the missile at different speed. It can be seen that the rotational speed has a little effect on the penetration process when it penetrates the first target. The variation of velocity, acceleration, and trajectory deviation angle with 
time is similar, and the curves coincide approximately. When the projectile penetrates the second target plate, the residual velocity of the missile increases, and the speed decrease, and the acceleration change curve closes. Ballistic offset angle is the maximum at $5000 \mathrm{r} / \mathrm{min}$ and minimum at $20000 \mathrm{r} / \mathrm{min}$, and the ballistic offset angle of the missile at $0 \mathrm{r} /$ $\mathrm{min}$ and $10000 \mathrm{r} / \mathrm{min}$ is approximately equal between the two working conditions above. This is due to the length of the penetrating missile far greater than the thickness of the metal target plate; the penetrating process can be regarded as the projectile body penetration of the metal sheet process, and the form of destruction is ductility perforated armor. When the missile body heads through the target plate, the projectile hole will be further expanded. The missile hole diameter is slightly larger than the projectile body diameter. With the penetrating, the sidewall of the missile body will no longer be in direct contact with the metal target plate. At this time, the missile body was penetrated resistance, and the flip torque disappeared; the body only under the original dynamic energy and gravity acceleration, in the missile body to break through the first target plate before the second target plate of this process, and the projectile body's velocity and approximate acceleration remain unchanged. The ballistic offset angle continues to increase with the speed direction after the first target plate is broken, and this process corresponds to the curve between 0.12 and $0.28 \mathrm{~ms}$ in Figures 9, 10 , and 11 . As the penetration proceeds, the penetration process starts again when the head of the missile touches the second plate. After the missile penetrated the first target, the warhead will erode and the pier will be thick. When the warhead becomes blunt, the velocity decreases and the acceleration increases obviously. The accumulation of trajectory offset angle will lead to further increase of offset angle. The above process corresponds to the curve after $t=0.28 \mathrm{~ms}$.

\subsection{Changes in Parameters at Different Positions of the Missile} Body. As the acceleration sensor of the fuze is arranged in different positions, the penetrating parameters obtained are also different. To understand the design law of rotating penetrating projectile, the following simulation analysis is carried out on this problem.

Condition 5 is still selected as the research object. The front, middle, and back positions on the projectile axis are selected as the measurement points, as shown Figure 12.

Figures 13,14, and 15 show the acceleration change slot over time in the $X, Y$, and $Z$ directions of the different positions of the missile. As can be seen from Figures 13 and 14 , the acceleration of the missile in the direction perpendicular to the penetration direction is obvious at points $\mathrm{A}$ and $\mathrm{C}$, showing two obvious peaks, and the direction of the two points is opposite. The reason is that, in the process of penetration, there will be an approximate deflection around the center of mass, and the deflection of its head and tail is opposite, resulting in the opposite acceleration direction of the two parts in the same direction simultaneously. When the deflection angle acceleration of the projectile is constant, the deflection acceleration is larger at

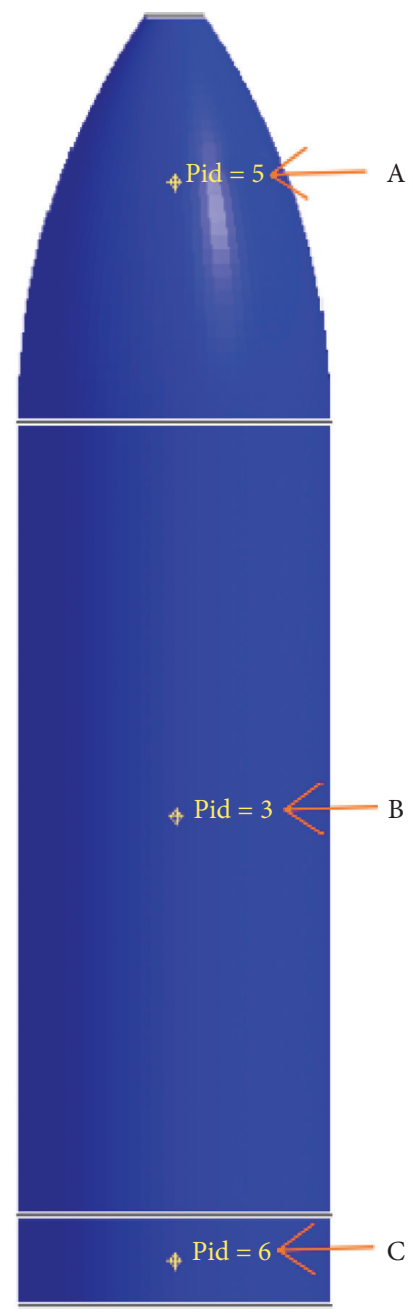

Figure 12: Missile parameter measurement point.

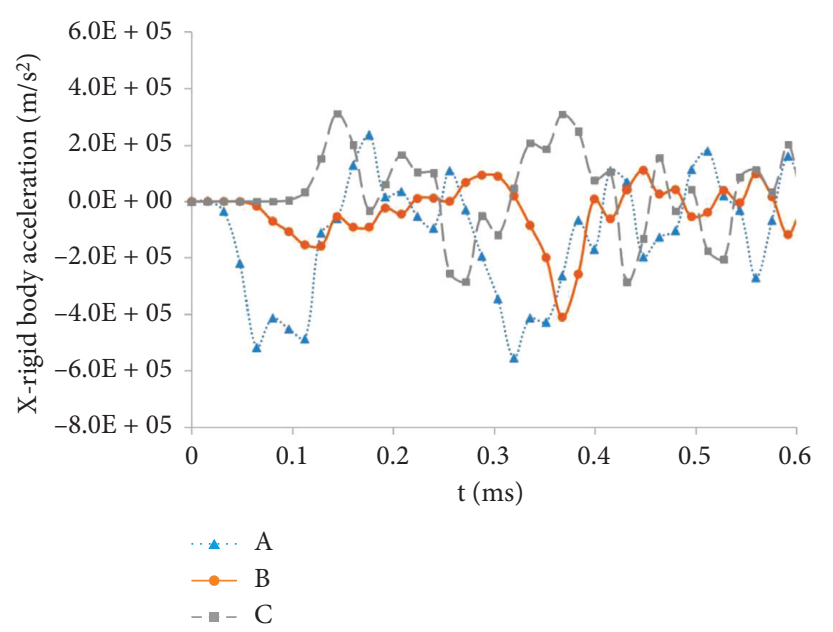

Figure 13: Acceleration curve in the $X$-direction at different positions of the missile.

the position far away from the centroid because the centroid of the missile is close to point B. Far away from the missile body, the center position is subjected to deflection, and acceleration is larger, so the head and tail of the missile 


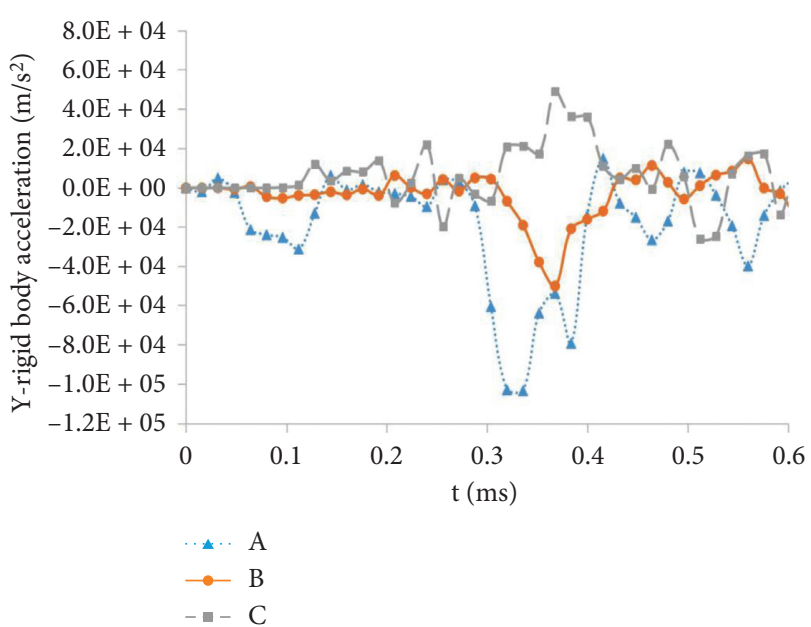

FIgURE 14: Acceleration curve in the $Y$-direction at different positions of the missile.

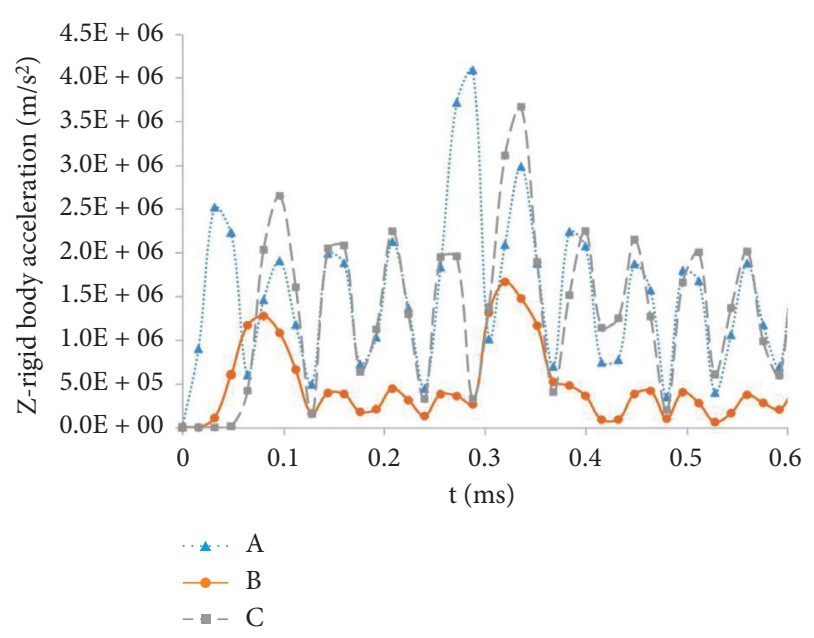

FIgURE 15: Z-directional acceleration curve at different positions of the missile.

perpendicular to the direction of the acceleration change sensing are more obvious. As plotted in Figure 15, the acceleration curve of the $B$ in the middle of the missile shows two distinct peaks in the Z-direction, which correspond to the acceleration of the two target layers when the missile invades, and the point $\mathrm{A}$ and $\mathrm{C}$ acceleration mutations are relatively not obvious.

This is due to the fact that the missile in the process of penetrating will be around its own deflection, the head and tail in the Z-direction of the acceleration component is significantly larger than the middle. By the acceleration vector synthesis principle, the missile deflection of the two parts of the acceleration interference in the Z-direction is larger and the central position is relatively small. Therefore, the central position of the missile body is more obvious to the acceleration of the body in the direction of penetration. Furthermore, when swirling into the arrangement of the fuze accelerometer of the intrusive ammunition, the accelerometer should be arranged as far as possible in the position of the relatively ballistic center.

\section{Conclusions}

The numerical results showed that (1) the residual velocity of rotating penetrator decreases with the compression of the relative distance between missile point and reinforcing ribs. (2) The acceleration of the missile penetrating the second target is larger than that of the first layer. (3) The deflection ballistic offset angle is affected by comprehensive factors. (4) The rotational speed of missile has less effect on precession penetration ammunition. (5) The acceleration perpendicular to the penetration direction is obviously perceived in the middle of the missile. The research results will provide a reference for the design of the rotating penetrating missile and fuze obtained above.

In this paper, vertical penetration is mainly considered, while oblique penetration and composite deck are rarely considered. For the problems, we will study them in another research.

\section{Data Availability}

The data used to support the findings of this study are available from the corresponding author upon request.

\section{Conflicts of Interest}

The authors declare that they have no conflicts of interest.

\section{Acknowledgments}

This work was supported by the Key Laboratory Open Research Fund Project of the Advanced Manufacturing Technology Laboratory in Shanxi under the grant XJZZ201704.

\section{References}

[1] J. Li, X. J. Li, and Z. Zhao, "Simulation on projectile with high rotating speed penetrating into the moving vehicular door," Theoretical and Applied Fracture Mechanics, vol. 47, no. 2, pp. 113-119, 2007.

[2] S. Fan, Z.-G. Chen, and X. Hou, "Numerical simulations and experimental study penetrating projectile on novel rotating," Journal of Projectiles Rockets, Missiles and Guidance, vol. 2, 2013.

[3] J. Cui, X. Chen, A. Tian et al., "Investigation of the penetration resistance of monolithic and double-layered steel plates," International Journal of Modern Physics B, vol. 33, Article ID 1940005, 2019.

[4] S. Dey, T. Børvik, X. Teng, T. Wierzbicki, and O. S. Hopperstad, "On the ballistic resistance of doublelayered steel plates: an experimental and numerical investigation," International Journal of Solids and Structures, vol. 44, no. 20, pp. 6701-6723, 2007.

[5] M. Grujicic, S. Ramaswami, and J. Snipes, "Computational investigation of ballistic-impact behavior and penetration resistance of a nacre-like ceramic/polymer laminated composite," International Journal of Structural Integrity, vol. 8, no. 1, pp. 79-107, 2017.

[6] O. A. Kudryavtsev and S. B. Sapozhnikov, "Numerical simulations of ceramic target subjected to ballistic impact using 
combined DEM/FEM approach," International Journal of Mechanical Sciences, vol. 114, pp. 60-70, 2016.

[7] C.-Y. Huang and Y.-L. Chen, "Design and impact-resistant analysis of functionally graded $\mathrm{Al}_{2} \mathrm{O}_{3}-\mathrm{ZrO}_{2}$ ceramic composite," Materials \& Design, vol. 91, pp. 294-305, 2015.

[8] P. J. Hazell, G. J. Appleby-Thomas, and S. Toone, "Ballistic compaction of a confined ceramic powder by a nondeforming projectile: experiments and simulations," Materials and Design, vol. 56, pp. 943-952, 2014.

[9] H. Mei, L. Zhang, and H. Xu, "Damage mechanism of a carbon-fiber ceramic composite during the step-loading indentation and its effect on the mechanical properties," Composites Part B: Engineering, vol. 56, pp. 142-148, 2014.

[10] B. G. Compton, E. A. Gamble, and F. W. Zok, "Failure initiation during the impact of metal spheres onto ceramic targets," International Journal of Impact Engineering, vol. 55, pp. 11-23, 2012.

[11] W. A. Gooch and R. G. O’Donnell, "Study of fragmentation in the ballistic impact of ceramics," International Journal of Impact Engineering, vol. 15, no. 5, pp. 605-618, 1994.

[12] Y. Li, H.-L. Yu, and X.-T. Rui, "Numerical study on penetration of rotating projectile into steel plate," Fire Control \& Command Control, vol. 39, no. 12, pp. 31-35+39, 2014.

[13] X. Li and L. Jiang, "Numerical study on penetration of a highspeed-rotating bullet into the moving sheet-metal plate," Explosion and Shock Waves, vol. 1, pp. 57-61, 2008.

[14] Z. Zhang and F. Huang, The Numerical Simulation for Semiarmor-piecing Anti-ship WarheadPenetrating the Structural Target with Rebar, pp. 406-410, Transaction of Beijing Institute of Technology, Beijing, China, 2003.

[15] Z. Duan, "Experimental and theoretical study on the end ballistics of semi-piercing projectiles on the penetration of reinforced targets," Explosion and Shock Waves, vol. 6, pp. 547-552, 2005.

[16] R. L. Woodward and S. J. Cimpoeru, "A study of the perforation of aluminum laminate targets," International Journal of Impact Engineering, vol. 21, no. 3, 1998. 